\title{
Food Nanoparticles and Intestinal Inflammation: A Real Risk?
}

\author{
Alina Martirosyan, Madeleine Polet, \\ Alexandra Bazes, Thérèse Sergent and \\ Yves-Jacques Schneider \\ Additional information is available at the end of the chapter \\ http://dx.doi.org/10.5772/52887
}

\section{Introduction}

Nanotechnology is a rapidly evolving field of research and industrial innovation with many potentially promising applications in agriculture, healthcare, engineering, processing, packaging or delivery of drugs or food supplements. Engineered nanomaterials (ENMs) already became part of our daily life as food packaging agents, drug delivery systems, therapeutics, biosensors, etc. In 2011, according to the Woodrow Wilson Nanotechnology Consumer Products Inventory, Ag nanoparticles (Ag-NPs) were the most commonly consumed ENMs, followed by $\mathrm{TiO}_{2}, \mathrm{SiO}_{2}, \mathrm{ZnO}, \mathrm{Au}, \mathrm{Pt}$, etc (http://www.nanotechproject.org). By the most recent definition of European Parliament and Council [1] 'nanomaterial' (NM) is any material that is characterized to have at least one dimension $\leq 100 \mathrm{~nm}$, or that comprises of separate functional parts either internal or on the surface, which have one or more dimensions $\leq 100$ $\mathrm{nm}$, including structures, e.g. agglomerates or aggregates, which may be larger than $100 \mathrm{~nm}$, but which retain the typical properties of nanoscale.

In many countries ENMs are already used as food supplements and in food packaging: (i) nanoclays as diffusion barriers [2]; (ii) Ag-NPs as antimicrobial agent [3,4]; (iii) silicates and aluminosilicates (E554, E556, E559) as anti-caking and anti-clumping agents and in toothpastes, cheeses, sugars, powdered milks, etc [5]; (iv) $\mathrm{TiO}_{2}$ (E171) for whitening and brightening, e.g. in sauces and dressings, in certain powdered foods [6], etc. According to FAO/WHO report [7] the ENMs have several current or projected applications in the agrofood sector: nanostructured food ingredients; nanodelivery systems; organic and inorganic 
nanosized additives; nanocoatings on food contact surfaces; surface functionnalized NMs; nanofiltration; nanosized agrochemicals; nanosensors; water decontamination, ...

With an increasing number of ENMs present in consumer and industrial products, the risk of human exposure increases and this may become a threat to human health and the environment [8]. Individual ENMs may lead to one or more endpoints, which are not unique to NMs, but which need to be taken into account, e.g. cytotoxicity, stimulation of an inflammatory response, generation of reactive oxygen species (ROS) and/or genotoxicity. Although the exact mechanism underlying NPs toxicity is yet to be elucidated, studies have suggested that oxidative stress and lipid peroxidation regulate the NP-induced DNA damage, cell membrane disruption and cell death [9-12]. It has been suggested that ROS, in turn, modulate intracellular calcium concentrations, activate transcription factors, induce cytokine production [13], as well as lead to increased inflammation [14,15]. Small sized metallic NPs, e.g. Ag-NPs, $\mathrm{TiO}_{2}$, Co-NPs may also cause DNA damage [16-20]. In vitro studies with different types of NPs (metal/metal oxide, $\mathrm{TiO}_{2}$, carbon nanotubes, silica) on various cell lines have demonstrated oxidative stress-related inflammatory reactions. It is believed that this response is largely driven by the specific surface area of the NPs and/or their chemical composition [21-25]. Typically, the biological activity of particles increases with the particle size decrease [26-29]. Moreover, depending on their chemistry, NPs show different cellular uptake, subcellular localization and ability to induce the ROS production [30]. On the contrary, there are also cases reported of NPs having anti-inflammatory properties, such as certain Ce oxide [31] and Ag-NPs [32]. Nanocrystalline Ag has been demonstrated to have antimicrobial and anti-inflammatory properties and was found to reduce colonic inflammation following oral administration in a rat model of ulcerative colitis, suggesting that nano-silver may have therapeutic potential for treatment of this condition [32].

To sum up, based on the information currently available, no generic assumptions can be made regarding the toxicity upon exposure to NMs, their endpoints and the implications of different organs and tissues.

\section{Behavior and fate of ENMs in the GIT}

The gastrointestinal tract (GIT) is a complex barrier-exchange system and is one of the most important routes for macromolecules to enter the body, as well as a key actor of the immune system. The epithelium of the small and large intestines is in close contact with ingested materials, which are absorbed by the villi. To date, studies on exposure, absorption and bioavailability are mainly focused on the inhalation and dermal routes, and little is known about the toxicokinetic and toxicodynamic processes following oral exposure, particularly in relation to ingestion of ENMs that are present in food.

ENMs can reach the GIT either after mucociliary clearance from the respiratory tract after being inhaled [33], or can be ingested directly in food, water, drugs, drug delivery devices, etc $[8,34]$. The dietary consumption of NPs in developed countries is estimated around $10^{12}$ particles/person per day, consisting mainly of $\mathrm{TiO}_{2}$ and mixed silicates [35]. 
It has been shown that several characteristics, such as (i) the particle size [36], (ii) surface charge [37], (iii) attachment of ligands [38,39], (iv) coating with surfactants [40], as well as $(v)$ the administration time and dose [41] affect the fate and extent of ENMs absorption in GIT. The published literature on the safety of oral exposure to food-related ENMs currently provides insufficient reliable data to allow a clear safety assessment of ENMs [42] that is connected primarily with inadequate characterization of ENMs [43]. For instance, it has been demonstrated that smaller particles cross the colonic mucus layer faster than larger ones [37]. The NPs kinetics in the GIT also depends strongly on their charge, i.e. positively charged latex particles remain trapped in the negatively charged mucus, while negatively charged ones diffuse across the mucus layer and their interaction with epithelial cells becomes possible [41].

NPs that pass the mucus barrier may be translocated through the intestinal epithelium, which will depend not only on physicochemical characteristics of NPs [36-41], but also on the physiological state of the GIT [44]. The translocation of NPs potentially used as food components through the GIT remains to be explored [45]. Much of the current knowledge concerning the potential toxicity of NPs has been gained from in vitro or in silico test systems. Following ingestion, translocation of particles across the GIT can occur via different pathways:

1. Endocytosis through 'regular' epithelial cells (NPs $<50$ - $100 \mathrm{~nm}$ ) [46].

2. Transcytosis via microfold (M) cell uptake at the surface of intestinal lymphoid tissue (NPs of $20-100 \mathrm{~nm}$ and small microparticles i.e. 100 - $500 \mathrm{~nm}$ ) [47]. M cells are specialized phagocytic enterocytes that are localized in intestinal lymphatic tissue - Peyer's Patches (PP). This transcytotic pathway occurs via vesicle formation at the apical (i.e. luminal) cell membrane that engulfs some extracellular material, which then moves across the cell, escaping therefore to fusion with lysosomes, fuses with the basolateral membrane (i.e. serosal) and releases the material at the opposite side of the intestinal barrier. The mechanism is size-dependent - the smaller the particle, the easier is the passage through the epithelium [48-50].

3. Persorption, where 'old' enterocytes are extruded from the villus into the gut lumen, leaving 'holes' in the epithelium, which allow translocation of even large particles, such as starch and pollen [51-53].

4. Another possible route by which NPs can gain access to the gastrointestinal tissue is the paracellular route across tight junctions (TJs) of the epithelial cell layer. TJs are remarkably efficient at preventing paracellular permeation, although their integrity can be affected by diseases, e.g. inflammation, and/or by metabolites (e.g. glucose), calcium chelators (e.g. citrate) [54] and even particle endocytosis [55].

All above-mentioned routes could be involved in NPs translocation. There are a number of published reports stating the involvement of different types of endocytosis in the process of NPs internalization: clathrin-mediated pathway, caveolin-mediated endocytosis and macropinocytosis for $\mathrm{TiO}_{2}$ [56], size-dependent endocytosis for Au-NPs [57]; endocytotic pathways were described for $\mathrm{SiO}_{2}[58,59]$ and $\mathrm{Ag}-\mathrm{NPs}$ [60], etc. 
Several studies demonstrated that the phenomenon of persorption is also true for NPs, e.g. in the case of colloidal Au-NPs [36]. Small and large NPs gain potentially access to this route, nevertheless its quantitative relevance remains low, as it seems to be very inefficient compared to the active uptake of particles by M-cells. For instance, it was indicated that one lymphoid follicle dome of the rabbit PP could transport about $10^{5}$ microparticles of $460 \mathrm{~nm}$ diameter in $45 \mathrm{~min}$ [61]. It could be assumed that for smaller particles this would be even more efficient.

Particulate uptake may occur not only via the M-cells of the lymphoid follicle-associated epithelium (FAE) in PP [49,62], but also via the normal intestinal enterocytes [46]. A number of reports on intestinal uptake of micro- and nanoparticles state that the uptake of inert particles occurs trans-cellularly through normal enterocytes and via M-cells [61,63-65], as well as, to a lesser extent, through paracellular pathway [66].

\section{Appropriate in vitro model of the intestinal barrier}

There are several recognized parameters currently used for in vitro cytotoxicity assessment of ENMs, such as cell viability, stress and inflammatory responses, genotoxicity, etc [67]. However, it should be noted that due to specific physicochemical properties of ENMs, currently existing in vitro toxicity assays may have limited use and the methods should be carefully designed in order to discard the influence of nano-sized materials on the assay itself [28]. The risk assessment is further impaired by the lack of standardized test systems that fulfil these criteria. According to the new European Chemicals Legislation (REACH), new test systems for toxicity screening of ENMs should be developed, e.g. cell culture systems that will better reflect in vivo toxicity parameters [68].

Human colon adenocarcinoma (Caco-2) cells reproducibly display a number of properties characteristic to differentiated enterocytes and are the most popular cell culture system for studying intestinal passage and transport $[69,70]$. Cultured Caco-2 cells differentiate spontaneously into polarized monolayers [71] that possess an apical brush border and express functional TJs, biotransformation enzymes and efflux pumps [72]. Caco-2 cells grow as a monolayer and fully differentiate also on semi-permeable membranes of bicameral inserts. This permits to separate the apical (AP) compartment from the basolateral (BL) one, reflecting the intestinal lumen and the serosal side, respectively [65]. Transport of molecules and ions from the AP to the BL side and vice versa requires the passage either through the cells (transcellular route) or between the cells through TJs (paracellular route).

The gut lining epithelium is for the most part impermeable to microorganisms and microparticles, except for the lymphoid FAE found in PP $[49,73,74]$. M cells are responsible for transport of antigens, bacteria, viruses, as well as micro- and NPs to the antigen presenting cells within and under the epithelial barrier as the first step in developing immune responses [75]. There is only an incomplete and inadequate understanding of the development and function of FAE, as well as of the genes and proteins responsible for their specialized functions. One potential approach to study such complex and specialized tissues is to use cell 
culture systems more precisely reproducing the features of the in vivo tissue. Kernéis et al. [76] demonstrated that co-culturing of Caco-2 cells with murine PP lymphocytes appears to convert Caco-2 cells into M-like cells, including enhanced transport of particles across the epithelium monolayer. The induction of this phenotype did not require direct cell contact, as it was also achieved via physically separated co-culturing of Caco-2 and human Burkitt's lymphoma (Raji B) cells in bicameral culture inserts [77]. Although it is not clear whether this model faithfully reproduces all of the features of in vivo $\mathrm{M}$ cell function, nevertheless studies have confirmed that Caco-2 cells co-cultivated with Raji B cells in vitro express several genes specifically expressed in FAE in vivo [78].

In an improved in vitro co-culture model in bicameral system Caco-2 cells were exposed to lymphocytes from the BL chamber. In a so-called 'inverted' model (Figure 1) the lymphocytes were shown to migrate into the monolayer and induce the conversion of the enterocyte phenotype into the M-cells one [76,79]. Recently, des Rieux et al. [65] characterized the inverted model and compared it with previously developed one [77]. According to these results, in the inverted model, the $\mathrm{M}$ cell conversion rate was estimated to range between 15 $30 \%$ (for comparison it was $<10 \%$ in the human FAE [80]). The comparison of the in vitro models revealed that the inverted model appears to be physiologically and functionally more reproducible and efficient than the normally oriented one [65]. Thus this improved model could be used to better characterize and understand the biological effects, absorption and transportation mechanisms of NPs in intestinal cells.

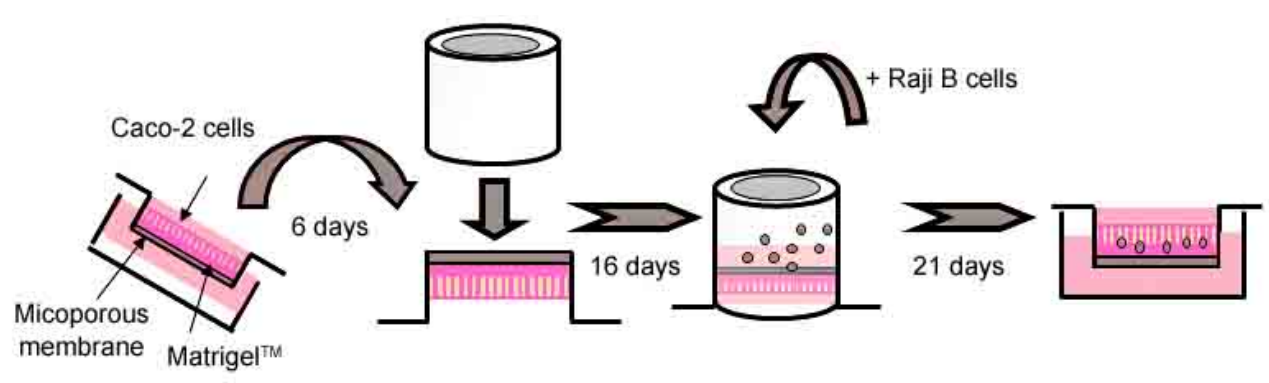

Figure 1. Co-culture model of Caco-2 and Raji B cells [63].

\section{Epithelial barrier integrity and inflammatory response under the influence of NPs}

During their differentiation epithelial cells develop junctional structures between the neighboring cells and form a tight protective barrier that restricts the absorption to some nutrients and substances while, in the meantime, provides a physical barrier impairing the permeation of pro-inflammatory molecules, e.g. pathogens, toxins, antigens and xenobiotics from 
the luminal environment into the mucosal tissues and circulatory system. This barrier comprises several structures [81], where the TJs are the most apical components of the junctional complex and are the main gatekeepers of the epithelial paracellular passage. TJ barrier disruption and increased paracellular permeability, followed by permeation of luminal pro-inflammatory molecules can activate the mucosal immune system, resulting in chronic inflammation and tissue damage [75]. Intestinal TJ barrier is evidenced to have a critical role in the pathogenesis of intestinal and systemic diseases [82-84]. Under physio-pathological conditions, pro-inflammatory cytokines, antigens and pathogens contribute to barrier impairment $[85,86]$. Considering the TJs integrity impairments under inflamed conditions, it could be assumed that NPs that lead to stress and/or inflammatory responses could also influence the TJs integrity.

Several methodological approaches allow measuring the barrier function in cell cultures, e.g. the evaluation of the transepithelial electrical resistance (TEER) and the passage of marker molecules, such as Lucifer Yellow (LY) [87]. Our results revealed that under the influence of Ag-NPs $<20 \mathrm{~nm}$, a disruption of the barrier integrity occurs. In figure 2A the TEER values of both mono- and co-cultures of Caco-2 cells after $3 \mathrm{~h}$ of incubation with different concentrations of Ag-NPs are shown. TEER values decreased as Ag-NPs concentration increased, even though the reduction was less obvious in co-culture conditions - a model that is closer to the physiological conditions of FAE.

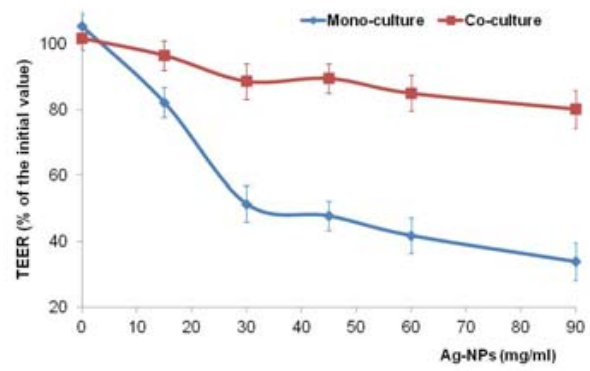

A

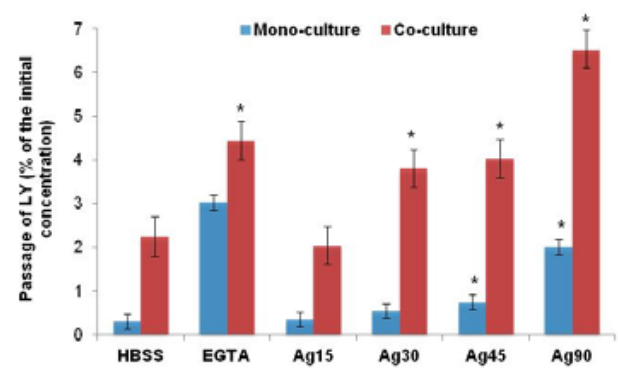

B

Figure 2. TEER values (A) and LY passage (B) of mono- and co-cultures of Caco-2 cells upon incubation with Ag-NPs (NM-300K, JRC repository, Ispra, IT) at $15-90 \mu \mathrm{g} / \mathrm{ml}$. Experiments were conducted on mono- and co-cultures (i.e. Caco-2 cells with Raji B lymphocytes) cultivated for 21 days in polycarbonate bicameral inserts with $3 \mu \mathrm{m}$ pore size (Transwell ${ }^{\mathrm{TM}}$, Corning Costar, NY) to reach a full differentiation and, for co-cultures, partial conversion into M like cells. TEER values were measured via Millicell-ERS volt-ohm meter (World Precision Instruments, Sarasota, FL) at the beginning and after $3 \mathrm{~h}$ incubation period with Ag-NPs. The transport of LY was observed during $3 \mathrm{~h}$ period with a 30 min sampling time from the BL compartment. Both the changes in TEER values $(P<0.0001)$ and the LY passage $(P<0.003)$ were calculated as a percentage from the initial value. Data represent the means \pm SEM of 4 independent experiments. *Samples significantly different from the control (results were considered significant at $\mathrm{P}<0,05$ ).

The passage of LY was evaluated by the amount of LY that passed from AP to BL compartment (Figure $2 \mathrm{~B}$ ). The presence of Ag-NPs increased the level of LY in the BL compartment that was dependent on the NP concentration. These results are in correlation with the NP- 
induced reduction of TEER values. Interestingly, in contrast to TEER results, the co-cultures had more elevated rate of LY passage than the corresponding mono-cultures.

To have an idea about the molecular mechanisms of the Ag-NPs-induced barrier integrity disruption, an immunostaining with confocal microscopy analysis of two TJs proteins occludin and ZO-1 was realized. As illustrated on Figure 3, in Ag-NP-treated cells the continuity of both occludin and ZO-1 was disrupted with the control comparison and the aggregation of both proteins was observed. It should further be noted that mono-cultures were more susceptible to the influence of Ag-NPs than co-cultures and the alterations in proteins distributions were more visible in mono-cultures. The immunostaining results in turn confirmed the TEER data, where a more obvious reduction was estimated in the case of mono-cultures (Figure 2).

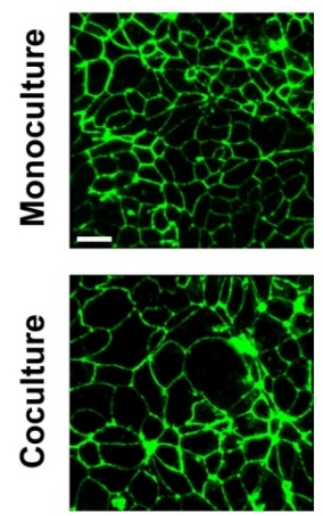

A
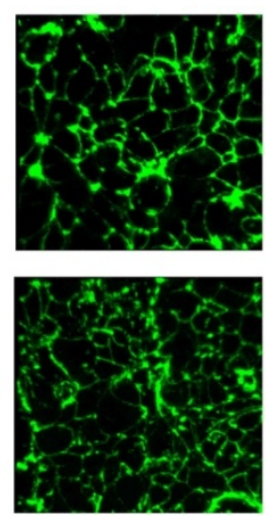

B

Occludin
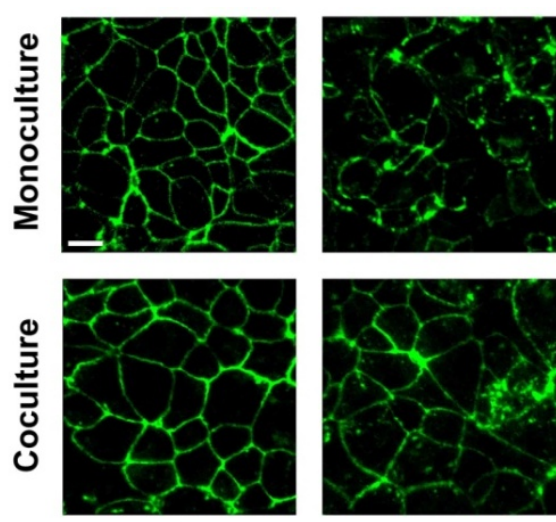

C

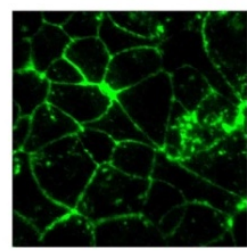

D

\section{ZO-1}

Figure 3. Subcellular localization of the occludin and ZO-1 TJs scaffolding proteins. Mono- and co-cultures of Caco-2 cells grown on bicameral inserts were treated with Ag-NPs $(45 \mu \mathrm{g} / \mathrm{ml})$ for $3 \mathrm{~h}$ and then processed for immunostaining $(B$ and $D)$. Untreated cells were used as controls ( $A$ and $C$ ). In order to visualize the occludin and ZO-1 mouse antiOccludin and mouse anti-ZO-1 (both from Invitrogen) were used as primary antibodies, as well as Alexa Fluor 488 goat anti-mouse (Invitrogen) as the secondary antibody. Images were collected by confocal laser scanning microscope; scale bars are 15 and $25 \mu \mathrm{m}$ for occludin and ZO-1 staining, respectively.

The observed changes were reversible at low Ag-NPs concentrations (up to $30 \mu \mathrm{g} / \mathrm{ml}$ ): the TEER values and TJs proteins distributions were recovered until the control level. Other NPs were also reported to possess the ability to open the TJs. For instance, the chitosan NPs were capable to open transiently and reversibly the epithelial TJs [88].

In contrast to Ag-NPs, we observed no change neither in TEER value and LY passage rate, nor TJs proteins distributions upon incubation of cell mono- and co-cultures with amorphous $\mathrm{SiO}_{2}<25 \mathrm{~nm}$ (NM-200, JRC repository, Ispra, IT) (results not shown). These findings provide additional evidence that the major input in the NPs-mediated barrier integrity disruption seems to belong to the charge of the NPs. Particularly, it has been previously report- 
ed that neutral and low concentrations of anionic NPs have no effect on blood-brain barrier integrity, in contrast to anionic NPs at high concentrations and cationic NPs [89]. A number of recent in vitro and in vivo studies highlight the importance of NPs surface charge for cellular uptake and biodistribution [90-92], indicating that for the majority of NPs the positive surface charge enhances cellular internalization [92-94]. The latter is likely linked to the adsorption of different bio-molecules at the surface of NPs, dependent on surface charge, as well as on chemical characteristics of NPs [95].

Another underlying condition in the TJs disruption is likely to be the cellular oxidative stress possibly induced by NPs [96]. Our results have shown that the fluorescence intensity of an oxidative stress indicator dichlorofluorescein was increased upon exposure of cells to Ag-NPs within a $3 \mathrm{~h}$ time period (Figure 4). The ROS generation induction was dependent on NPs concentration reaching from about 1,5 to 3-fold increase, as compared with the untreated cells. Thus one mechanism of toxicity of Ag-NPs could likely be mediated by oxidative stress, already reported to be involved in the modulation of TJs integrity [97].

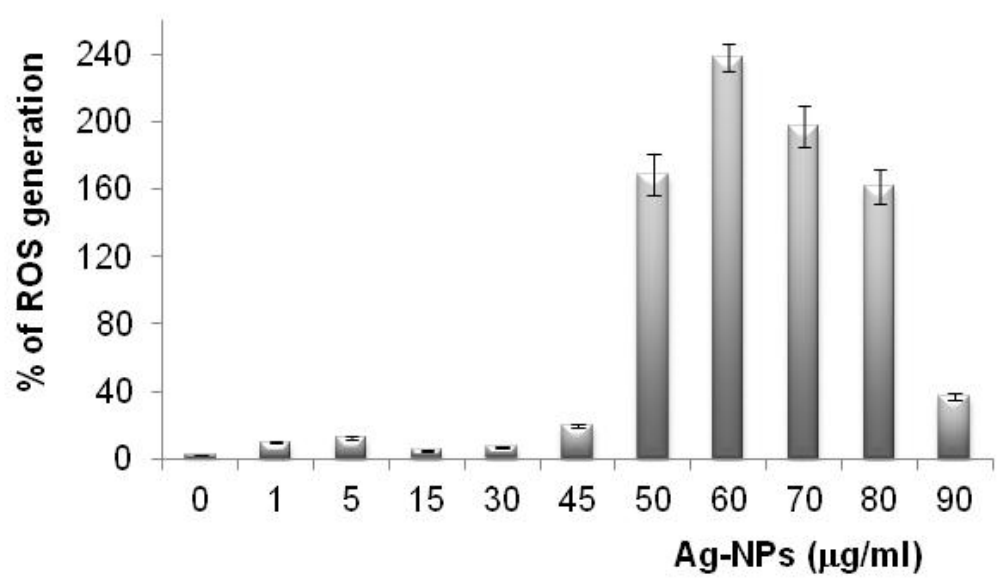

Figure 4. Effect of Ag-NPs $(5-90 \mu \mathrm{g} / \mathrm{ml})$ on intracellular ROS generation in Caco-2 cells. The ROS generation was investigated using the dichlorofluorescein (DCFH) assay. After being oxidized by intracellular oxidants, DCFH becomes DCF and emits fluorescence, quantification of which is a reliable estimation of overall oxygen species generation. The intracellular ROS level is presented as a percentage of the corresponding initial value after incubation together with NPs during $3 \mathrm{~h}$ at $37^{\circ} \mathrm{C}$. Data represent means \pm SEM of 3 experiments with 3 different samples per condition, $P<0.0001$.

Altogether, the results reveal that some NPs, e.g. chitosan or Ag-NPs may enhance the epithelial barrier permeability and could therefore serve as an effective carrier for oral drug delivery [44]. However, it should be noted that the epithelial permeability increase in turn might favor the systemic absorption of ENMs, toxins and other xenobiotics, and would likely cause immune activation. 


\section{Potential toxicity of ENMs in the case of altered intestinal physiology}

It has been reported that the exposure to some NPs is associated with the occurrence of autoimmune diseases, such as systemic lupus erythematosus, scleroderma, and rheumatoid arthritis [35]. Diseases, such as diabetes, may also lead to an increased absorption of particles in the GIT [41]. Furthermore, inflammation may lead to the uptake and translocation of particles of up to $20 \mathrm{~nm}$ [98]. Thus, an issue to be considered in relation to ENMs ingestion is a possible increase in their intestinal absorption in the case of systemic exposures, such as in Inflammatory Bowel Disease (IBD) and/or Crohn's disease (CD), which represent chronic disorders characterized by recurrent and serious inflammation of the GIT [99]. Crohn's disease affects primarily people in developed countries, where the highest incidence rates and prevalence for CD and ulcerative colitis (UC) have been reported from northern Europe, the United Kingdom and North America [100] with a frequency of 1 in 1,000 people in the Western world [5]. However, reports of increasing incidence and prevalence from other areas of the world, e.g. southern or central Europe, Asia, Africa, and Latin America state the progressive nature and worldwide rise of these diseases [100].

An abnormal intestinal barrier function plays a pivotal role in IBD [101]. Increased intestinal permeability has been reproducibly described in patients with $C D$, which is likely a predisposing factor to the pathogenesis and impaired epithelial resistance [102,103]. A barrier dysfunction has been reported in the colonic mucosa of patients with Irritable Bowel Syndrome (IBS), which results from increased paracellular permeability, presumably by an altered expression of ZO-1 [104]. Moreover, stress is believed to contribute to induction of IBS and recurrence of intestinal inflammation and can increase the paracellular permeability [105]. It should be noted that mediators of inflammation, such as ROS, endotoxins (lipopolysaccharides) and cytokines are able to provoke the disruption of TJs and thereby increase the paracellular permeability [97]. Significant changes in epithelial TJs structure and function were also observed in UC $[106,107]$. Thus the altered intestinal permeability could certainly be a result of disease progression, but there is evidence that it might also be the primary causative event.

Recently it was suggested that there could be an association between high levels of dietary NPs uptake and CD. Experimental results indicate that the accumulation of insoluble NPs in humans may be responsible for the compromised gastrointestinal functioning, as described in the case of CD and UC [5]. Microscopy studies have also shown that macrophages located in lymphoid tissue can uptake NPs, e.g. spherical anatase $\left(\mathrm{TiO}_{2}\right)$ with size of 100-200 nm from food additives, aluminosilicates of 100-400 nm typical of natural clay, and environmental silicates of 100-700 nm [108]. According to another study, some insoluble NPs, such as $\mathrm{TiO}_{2}, \mathrm{ZnO}$ and $\mathrm{SiO}_{2}$, upon their absorption and passage across the GIT, come into contact with and adsorb calcium ions and lipopolysaccharides. The resulting NPs-calcium-lipopolysaccharide conjugates activate both peripheral blood mononuclear cells and intestinal phagocytes, which are usually resistant to stimulation [109].

Despite the insufficiency of data linking the NPs consumption to the initiation of CD and $\mathrm{UC}$, it seems that particles of $0.1-1.0 \mu \mathrm{m}$ may be adjuvant triggers for the exacerbation of 
these diseases [110]. Micro and NPs have been constantly found in organs, e.g. in colon tissue and blood of patients affected by cancer, CD, and UC, while in healthy subjects NPs were absent [111]. Some evidence suggests that dietary NPs may exacerbate inflammation in $\mathrm{CD}$ [6]. More precisely, some members of the population may have a genetic predisposition where they are more affected by the intake of NPs, and therefore develop CD [9]. It has been also reported that micro- and NPs in colon tissues may lead to cancer and CD progression [111]. By contrast, a diet low in calcium and exogenous micro- and NPs has been shown to alleviate the symptoms of CD [5]. This analysis is still controversial, with some proposing that an abnormal response to dietary NPs may be the cause of this disease, and not an excess intake [6].

Although there is a clear association between particle exposure/uptake and CD, little is known of the exact role of the phagocytosing cells in the intestinal epithelium and particularly of the pathophysiological role of M cells. It has been shown that $\mathrm{M}$ cells are lost from the epithelium in the case of CD. Other studies found that endocytotic capacity of M cells is induced under various immunological conditions, e.g. a greater uptake of particles of $0.1-$ $10 \mu \mathrm{m}$ has been demonstrated in the inflamed colonic mucosa of rats compared to non-ulcerated tissue [109,112].

Thus more vulnerable members of the population, i.e. those with pre-existing digestive disorders, may potentially be more affected by the presence of ENMs, although, in contrast, ENMs may offer many potential routes to therapies for the same diseases. The diseases associated with gastrointestinal uptake of NPs, such as CD and UC have no cure and often require surgical intervention. Treatments are aimed at maintaining the disease in remission and mainly consist of anti-inflammatory drugs and specially formulated liquid meals [5]. If dietary NPs are conclusively shown to cause these chronic diseases, their use in food should be avoided or strictly regulated.

\section{Potential health risks/benefits of nanotechnology-based food materials}

The absorption, distribution, metabolism and excretion (ADME) parameters are likely to be influenced by the aggregation, agglomeration, dispersability, size, solubility, and surface area, charge and physico-chemistry of NPs [113]. Amongst these parameters the size, chemical composition and surface treatment appear to be the most critical ones for nanotoxicity issues [114]. Chemical composition, beside the chemical nature of the NP itself, also includes the surface coating of the NPs [115]. Coatings can be used to stabilize the NPs in solution, to prevent clustering or to add functionality to the NPs, depending on its intended use. Surface coatings can influence the reactivity of the NPs in various media, including water, biological fluids and laboratory test media [116,117]. From this point of view the interaction of NPs with food components is another aspect that may need consideration and about which little information is currently available. The possible interaction of food components may alter the physicochemical properties of ENMs that in turn may influence their passage through the GIT and their ADME properties. 
ENMs, with their very large surface areas, may adsorb bio-molecules on their surface upon contact with food and/or biological fluids to form a bio-molecular "corona" $[96,118]$. Depending on the nature of the corona, the behavior of the NPs may differ, and there could be the potential for novel toxicities non-characteristic neither for the noncoated NPs, nor for the adsorbed biological material. These bio-molecules include proteins, lipids, sugars, different secondary metabolites and it is those interactions that may actually determine how ENMs will interact with living systems. Thus, the foregoing information on the food should be considered carefully, taking into account its major ingredients or components, which have physiological properties likely to influence the absorption/translocation of ENMs in the GIT.

Several studies have demonstrated that various food components provide beneficial anti-inflammatory and anti-mutagenic effects in the GIT. Although the information regarding these effects on intestinal TJ barrier integrity is limited, some results are available e.g. for glutamine [119,120] and fatty acids [121-123]. A growing number of data suggest the potential protective effect of phenolic compounds on the epithelial barrier function and their antiinflammatory properties [124,125]. In particular, certain flavonoids that represent a part of human daily nutrition, e.g. epigallocatechin gallate, genistein, myricetin, quercetin and kaempferol are reported to exhibit promotive and protective effects on intestinal TJ barrier $[124,126]$.

We have observed (unshown results) that quercetin attenuates the cytotoxic effect of AgNPs on Caco-2 cells, as well as allows recovering of the epithelial barrier function, which was evidenced by the recovery up to the initial value of the TEER and the LY passage rate in both mono- and co-cultures. The immunostaining analysis of occludin and ZO-1 also revealed the recovery of the protein distributions in the presence of quercetin, which additionally suggests the protective effect of the latter upon the harmful effects of Ag-NPs. In a similar study it was reported that positively charged Ni-NPs can efficiently enhance the permeation and uptake of quercetin into cancer cells, which can have important biomedical and chemotherapeutic applications [127].

A number of published reports indicate the potential application of antioxidants $[10,128-130]$ and anti-inflammatory drugs $[6,131]$ that are able to treat the adverse health effects caused by NPs. For instance, berberine, an alkaloid with a potential biomedical application, has been shown to attenuate TJ barrier defects induced by TNF- $\alpha$, known to disrupt TJ integrity in IBD [132]. It has been reported that rats that underwent instillation of NPs into the lungs together with an antioxidant, i.e. nacystelin, showed an inflammation decrease up to $60 \%$ in comparison to those exposed to NPs alone [10].

To have an idea about the state of Ag-NPs in the presence of quercetin, NPs were characterized by transmission electron microscopy (TEM) (Figure 5). It could be seen that in the presence of quercetin a "capping" of Ag-NPs occurs, which confirms already existing data on Ag-NPs stabilization with reducing agents. Surface-active molecules, such as terpenoids and/or reducing sugars are believed to stabilize the NPs in the solutions, i.e. they are believed to react with the silver ions $\left(\mathrm{Ag}^{+}\right)$and stabilize the Ag-NPs $[133,134]$. Flavonoids have been suggested to be responsible for the reduction of $\mathrm{Ag}^{+}$to $\mathrm{Ag}-\mathrm{NPs}$ [135]. Fatty acids such 
as stearic, palmitic and lauric acids are used as agents for the formation and stabilization of Ag-NPs [136].
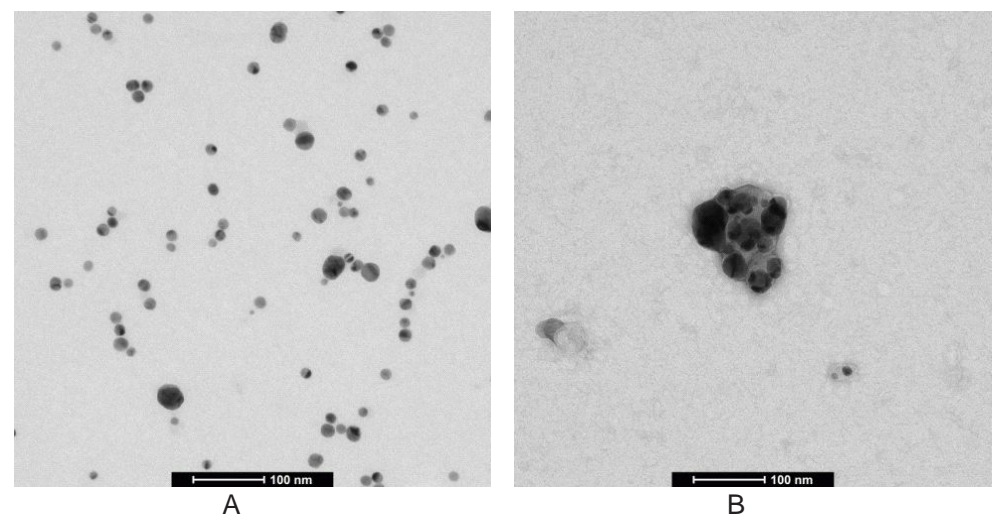

Figure 5. TEM analysis of Ag-NPs $<20 \mathrm{~nm}(\mathrm{NM}-300 \mathrm{~K})$ alone $(\mathrm{A})$ and in the presence of quercetin (B). The average size of Ag-NPs was about $20 \mathrm{~nm}$, scale bar: $100 \mathrm{~nm}$. NPs were characterized by transmission electron miscroscopy (TEM) (Technai Spirit TEM, FEI Company, Eindhoven, NL) by Dr. J. Mast at the Electron Microscopy Unit of the Veterinary and Agrochemical Research Centre VAR-CODA-CERVA, Uccle, BE.

Another major phenolic compound present in human diet is resveratrol, which possesses many beneficial health effects [137-141]. Considering abundance and health-promoting effects of resveratrol, we have also investigated its potential protective activity against the AgNP-induced cytotoxicity. The results indicated no protective effect of resveratrol and moreover, at a concentration of $100 \mu \mathrm{M}$, non-toxic by itself, it increased the toxic effect of Ag-NPs, illustrating a synergistic effect.

To conclude, it could be assumed that phenolic compounds, depending on the nature and concentration, may exhibit different effects on cells in the presence on NPs. This is not surprising, as it is known that these substances, depending on concentration, may exhibit both beneficial and toxic effects [141].

\section{Future perspectives}

Nanotechnology offers a wide range of opportunities for the development of innovative products and applications in agriculture, food production, processing, preservation and packaging. However, the present state of knowledge still contains many gaps preventing risk assessors from establishing the safety for many of the possible food related applications of nanotechnology [142]. Currently the routine assessment of ENMs in situ in the food or feed matrix is not possible, as well as equally impossible to determine physicochemical state of ENMs, which increases the uncertainty in the exposure assessment. Complex matrices present in the food complicate the detection and characterization of 
ENMs in final food/feed products, which itself contain a wide range of natural structures in the nano-size scale. The information on the potential of ENMs to cross the epithelial barriers, such as the GIT, blood-brain, placenta and blood-milk barriers are also important for hazard identification. It is also clear that the evaluation of the pro-inflammatory potential of ENMs is another issue of current importance, as the inflammation itself is associated with a number of high frequency diseases, e.g. cancer, diabetes, bowel diseases, etc.

From the above discussion and the research presented in this review, the need for more toxicology research on manufactured ENMs is clear. In addition to standard tests, there is a need to develop appropriate and rapid screening methods to be able to control the exposure level, as well as improved models that will permit to assess the toxicity and allow better understanding of the mechanisms that are involved. Employment of developed and well characterized in vitro cell culture systems may be relevant for evaluation of gut and immune responses to ENMs and to adapt conditions to specific health conditions or to consumer groups with special needs, such as in the case of bowel diseases. Further studies are necessary to assess whether the characteristic daily intake of ENMs may exacerbate or trigger disease symptoms in subjects with increased susceptibility, such as inflamed state of the GIT in the case of IBD, CD, UC, or even be its cause.

Another aspect deserving thorough investigation is the possible interaction of ENMs with food/feed components, which in turn could influence the overall behavior and effect of not only ENMs, but also the bioavailability of food components.

\section{Acknowledgments}

Authors thank to Dr. Jan Mast, head of the Electron Microscopy Unit in VAR-CODA-CER VA, Uccle, Belgium for scientific and technical support in the realization of Transmission Electron Microscopy analysis, as well as to the Biological Imaging Platform (IMAB) of the Université Catholique de Louvain (Louvain-la-Neuve, Belgium) for the realization of the confocal microscopy. This study was funded by the Belgian Federal Public Service and Belgian Federal Science Policy (BELSPO).

\section{Author details}

Alina Martirosyan, Madeleine Polet, Alexandra Bazes, Thérèse Sergent and Yves-Jacques Schneider

Institute of Life Sciences (Laboratory of Cellular, Nutritional and Toxicological Biochemistry) UCLouvain, Louvain-la-Neuve, Belgium 


\section{References}

[1] Regulation (EU) No 1169/2011 of the European Parliament and of the Council of 25 October 2011 on the provision of food information to consumers. Official Journal of the European Union 2011;L304 18-63.

[2] Annual report of the Food Safety Authority of Ireland (FSAI) 2008. The relevance for food safety of applications of nanotechnology in the Food and Feed Industries. Available from http://www.fsai.ie/resources_and_publications/annual_reports.html.

[3] Sanguansri P, Augustin MA. Nanoscale materials development - a food industry perspective. Trends in Food Science \& Technology 2006;17(10) 547-556.

[4] Chaudhry Q, Aitken R, Scotter R, Blackburn J, Ross B, Boxall A, Castle L, Watkins R. Applications and implications for nanotechnologies in the food sector. Food Additives and Contaminants 2008;25(3) 241-258.

[5] Lomer M, Thompson R, Powell J. Fine and ultrafine particles of the diet: influence on the mucosal immune response and association with Crohn's disease. Proceedings of the Nutrition Society 2002;61(1) 23-30.

[6] Lomer M, Hutchinson C, Volkert S, Greenfield S, Catterall A, Thompson R, Powell J. Dietary sources of inorganic microparticles and their intake in healthy subjects and patients with Crohn's disease. British Journal of Nutrition 2004;92(6) 947-955.

[7] Meeting report of the Food and Agriculture Organization of the United Nations and World Health Organization (FAO/WHO) expert meeting on the application of nanotechnologies in the food and agriculture sectors: potential food safety implications. 2010. Available from http://www.fao.org/docrep/012/i1434e/i1434e00.pdf.

[8] Oberdörster G, Maynard A, Donaldson K, Castranova V, Fitzpatrick J, Ausman K, Carter J, Karn B, Kreyling W, Lai D, Olin S, Monteiro-Riviere N, Warheit D, Yang H. Principles for characterizing the potential human health effects from exposure to nanomaterials: elements of a screening strategy. Particle and Fibre Toxicology 2005a; 28.

[9] Oberdörster E. Manufactured nanomaterials (Fullerenes, C60) induce oxidative stress in the brain of juvenile largemouth bass. Environmental Health Perspectives 2004;112(10) 1058-1062.

[10] Donaldson K, Stone V. Current hypotheses on the mechanisms of toxicity of ultrafine particles. Annali dell'Istituto Superiore di Sanita 2003;39(3) 405-410.

[11] Sayes C, Gobin A, Ausman K, Mendez J, West J, Colvina V. Nano-C60 cytotoxicity is due to lipid peroxidation. Biomaterials 2005;26(36) 7587-7595.

[12] Reeves J, Davies S, Dodd NJ, Jha A. Hydroxyl radicals $(\mathrm{OH})$ are associated with titanium dioxide $\left(\mathrm{TiO}_{2}\right)$ nanoparticle-induced cytotoxicity and oxidative DNA damage in fish cells. Mutation Research 2008;640(1-2) 113-122. 
[13] Brown D, Donaldson K, Borm P, Schins R, Dehnhardt M, Gilmour P, Jimenez L, Stone V. Calcium and ROS-mediated activation of transcription factors and TNF-alpha cytokine gene expression in macrophages exposed to ultrafine particles. Am. J. Physiology Lung Cellular and Molecular Physiology 2004;286(2) L344-L353.

[14] Brown D, Donaldson K, Stone V. Effects of PM10 in human peripheral blood monocytes and J774 macrophages. Respiratory Research 2004;5 29.

[15] Long H, Shi T, Borm P J, Määttä J, Husgafvel-Pursiainen K, Savolainen K, Krombach F. ROS-mediated TNF-alpha and MIP-2 gene expression in alveolar macrophages exposed to pine dust. Particle Fibre Toxicology 2004;1(1) 3.

[16] Kim S, Choi J, Choi J, Chung K, Park K, Yi J, Ryu D. Oxidative stress-dependent toxicity of silver nanoparticles in human hepatoma cells. Toxicology In Vitro 2009;(6) 1076-1084

[17] Gurr J, Wang A, Chen C, Jan K. Ultrafine titanium dioxide particles in the absence of photoactivation can induce oxidative damage to human bronchial epithelial cells. Toxicology 2005;213(1-2) 66-73.

[18] Mroz R, Schins R, Li H, Jimenez L, Drost E, Holownia A, MacNee W, Donaldson K. Nanoparticle-driven DNA damage mimics irradiation-related carcinogenesis pathways. European Respiratory Journal 2008;31(2) 241-251.

[19] Rahman Q, Lohani M, Dopp E, Pemsel H, Jonas L, Weiss D, Schiffmann D. Evidence that ultrafine titanium dioxide induces micronuclei and apoptosis in syrian hamster embryo fibroblasts. Environmental Health Perspectives 2002;110(8) 797-800.

[20] Papageorgiou I, Brown C, Schins R, Singh S, Newson R, Davis S, Fisher J, Ingham E, Case C. The effect of nano- and micron-sized particles of cobalt-chromium alloy on human fibroblasts in vitro. Biomaterials 2007;28(19) 2946-2958.

[21] Ghio A, Stonehuerner J, Dailey L, Carter J. Metals associated with both the watersoluble and insoluble fractions of an ambient air pollution particle catalyze an oxidative stress. Inhalation Toxicology 1999;11(1) 37-49.

[22] Hussain S, Hess K, Gearhart J, Geiss K, Schlager J. In vitro toxicity of nanoparticles in BRL3A rat liver cells. Toxicology In Vitro 2005;19(7) 975-983.

[23] Lin W, Huang Y-W, Zhou X-D, Ma Y. In vitro toxicity of silica nanoparticles in human lung cancer cells. Toxicology and Applied Pharmacology 2006;217(3) 252-259

[24] Pulskamp K, Diabaté S, Krug H. Carbon nanotubes show no sign of acute toxicity but induce cellular reactive oxygen species in dependence on contaminants. Toxicology Letters 2007;168(1) 58-74.

[25] Singh S, Shi T, Duffin R, Albrecht C, van Berlo D, Höhr D, Fubini B, Martra G, Fenoglio I, Borm P, Schins R. Endocytosis, oxidative stress and IL-8 expression in human lung epithelial cells upon treatment with fine and ultrafine $\mathrm{TiO}_{2}$ : Role of the specific 
surface area and of surface methylation of the particles. Toxicology and Applied Pharmacology 2007;222(2) 141-151

[26] Borm P, Robbins D, Haubold S, Kuhlbusch T, Fissan H, Donaldson K, Schins R, Stone V, Kreyling W, Lademann J, Krutmann J, Warheit D, Oberdorster E. The potential risks of nanomaterials: a review carried out for ECETOC. Particle and Fibre Toxicology 2006;3 11 .

[27] Card J; Zeldin D, Bonner J, Nestmann E. Pulmonary applications and toxicity of engineered nanoparticles. Am. Journal of Physiology, Lung Cellular and Molecular Physiology 2008;295(3) L400-411.

[28] Nel A, Xia T, Madler L, Li N. Toxic potential of materials at the nanolevel. Science 2006; 311(5761) 622-627.

[29] Oberdörster G, Oberdörster E, Oberdörster J. Nanotoxicology: an emerging discipline evolving from studies of ultrafine particles. Environmental Health Perspectives 2005b;113(7) 823-839.

[30] Xia T, Kovochich M, Brant J, Hotze M, Sempf J, Oberley T, Sioutas C, Yeh J, Wiesner $\mathrm{M}, \mathrm{Nel} \mathrm{A}$. Comparison of the abilities of ambient and manufactured nanoparticles to induce cellular toxicity according to an oxidative stress paradigm. Nano Letters 2006;6(8) 1794-1807.

[31] Tsai Y, Oca-Cossio J, Agering K, Simpson N, Atkinson M, Wasserfall C, Constantinidis I, Sigmund W. Novel synthesis of cerium oxide nanoparticles for free radical scavenging. Nanomedicine 2007;2(3) 325-232.

[32] Bhol K, Schechter P. Effects of nanocrystalline silver (NPI 32101) in a rat model of ulcerative colitis. Digestive Diseases and Sciences 2007;52(10) 2732-4272.

[33] Takenaka S, Karg E, Roth C, Schulz H, Ziesenis A, Heinzmann U, Schramel P, Heyder J. Pulmonary and systemic distribution of inhaled ultrafine silver particles in rats Environmental Health Perspectives 2001;109(Suppl. 4) 547-551.

[34] Hagens W, Oomen A, de Jong W, Cassee F, Sips A. What do we (need to) know about the kinetic properties of nanoparticles in the body? Regulatory Toxicology and Pharmacology 2007;49(3) 217-219.

[35] Buzea C, Pacheco I, Robbie K. Nanomaterials and nanoparticles: sources and toxicity. Biointerphases 2007;4 MR17-71.

[36] Hillyer J, Albrecht R. Gastrointestinal persorption and tissue distribution of differently sized colloidal gold nanoparticles. Journal of Pharmaceutical Sciences 2001;90(12) 1927-1936.

[37] Jani P, Halbert GW, Langridge J, Florence A. The uptake and translocation of latex nanospheres and microspheres after oral administration to rats. Journal of Pharmacy and Pharmacology 1989;41(12) 809-812. 
[38] Hussain N, Florence A. Utilizing bacterial mechanisms of epithelial cell entry: invasin-induced oral uptake of latex nanoparticles. Pharmaceutical Research 1998;15(1) 153-156.

[39] Hussain N, Jani P, Florence A. Enhanced oral uptake of tomato lectin conjugated nanoparticles in the rat. Pharmaceutical Research 1997;14(5) 613-618.

[40] Hillery A, Jani P, Florence A. Comparative, quantitative study of lymphoid and nonlymphoid uptake of $60 \mathrm{~nm}$ polystyrene particles. J of Drug Targeting 1994;2(2) 151-156

[41] Hoet P, Bruske-Hohlfeld I, Salata O. Nanoparticles - known and unkown health risks. Journal of Nanobiotechnology 2004;2(1) 12-27.

[42] Card J, Jonaitis T, Tafazoli S, Magnuson B. An appraisal of the published literature on the safety and toxicity of food-related nanomaterials. Critical Reviews in Toxicology 2011;41(1) 20-49.

[43] Magnuson B, Jonaitis T, Card J. A brief review of the occurrence, use, and safety of food-related nanomaterials. Journal of Food Science (2011;76(6) R126-133.

[44] Des Rieux A, Fievez V, Garinot M, Schneider Y-J, Preat V. Nanoparticles as potential oral delivery systems of proteins and vaccines: a mechanistic approach. Journal of Control Release 2006;116(1) 1-27.

[45] European Food Safety Authority (EFSA): Scientific Opinion of the Scientific Committee on the Potential Risks Arising from Nanoscience and Nanotechnologies on Food and Feed Safety. 2009. Available from http://www.efsa.europa.eu/EFSA/Scientific_Opinion/sc_op_ej958_nano_en,0.pdf?ssbinary=true

[46] Kalgaonkar S, Lonnerdal B. Receptor-mediated uptake of ferritin-bound iron by human intestinal Caco-2 cells. Journal of Nutritional Biochemistry 2009; 20(4) 304-311.

[47] Des Rieux A, Ragnarsson EG, Gullberg E, Preat V, Schneider Y-J, Artursson P. Transport of nanoparticles across an in vitro model of the human intestinal follicle associated epithelium. European Journal of Pharmaceutical Sciences 2005;25(4-5) 455-465.

[48] Seifert J, Haraszti B, Sass W. The influence of age and particle number on absorption of polystyrene particles from the rat gut. J of Anatomy 1996;189(Pt 3) 483-486.

[49] Gebert A, Rothkotter H, Pabst R. M cells in Peyer's patches of the intestine. International Review of Cytology 1996;167 91-159.

[50] Beier R, Gebert A. Kinetics of particle uptake in the domes of Peyer's patches. Am Journal of Physiology 1998;275(1 Pt 1) G130-137.

[51] Bockmann J, Lahl H, Eckert T, Unterhalt B. Blood titanium levels before and after oral administration titanium dioxide. Pharmazie 2000;55(2) 140-143.

[52] Volkheimer G. Passage of particles through the wall of the gastrointestinal tract. Environmental Health Perspectives 1974;9 215-225. 
[53] Volkheimer G. Persorption of microparticles. Pathologe 1993;14(5) 247-252.

[54] Powell J, Whitehead M, Lee S, Thompson R. Mechanisms of gastrointestinal absorption: dietary minerals and the influence of beverage ingestion. Food Chemistry 1994;51(4) 381-388.

[55] Moyes S, Smyth S, Shipman A, Long S, Morris J, Carr K. Parameters influencing intestinal epithelial permeability and microparticle uptake in vitro. International Journal of Pharmacology 2007;337(1-2) 133-141.

[56] Thurn K, Arora H, Paunesku T, Wu A, Brown E, Doty C, Kremer J, Woloschak G. Endocytosis of titanium dioxide nanoparticles in prostate cancer PC-3M cells. Nanomedicine 2011;7(2) 123-130.

[57] Wang S, Lee C, Chiou A. Wei P. Size-dependent endocytosis of gold nanoparticles studied by three-dimensional mapping of plasmonic scattering images. Journal of Nanobiotechnology 2010;8 33

[58] Sun W, Fang N, Trewyn B, Tsunoda M, Slowing I, Lin V, Yeung E. Endocytosis of a single mesoporous silica nanoparticle into a human lung cancer cell observed by differential interference contrast microscopy. Analytical and Bioanalytical Chemistry 2008;391(6) 2119-2125.

[59] Hu L, Mao Z, Zhang Y, Gao C. Influences of size of silica particles on the cellular endocytosis, exocytosis and cell activity of HepG2 cells. Journal of Nanoscience Letters 2011;1(1)1-16.

[60] Kim S, Choi I. Phagocytosis and endocytosis of silver nanoparticles induce interleukin-8 production in human macrophages. Yonsei Medical Journal 2012;53(3) 654-657.

[61] Jepson M, Simmons N, Savidge T, James P, Hirst B. Selective binding and transcytosis of latex microspheres by rabbit intestinal $\mathrm{M}$ cells. Cell and Tissue Research 1993;271(3) 399-405.

[62] Seifert J, Sass W. Intestinal absorption of macromolecules and small particles. Digestive Diseases 1990;8(3) 169-178.

[63] Florence A, Hussain N. Transcytosis of nanoparticle and dendrimer delivery systems: evolving vistas. Advanced Drug Delivery Reviews 2001;50(Suppl.1) S69-S89.

[64] Hussain N, Jaitley V, Florence A. Recent advances in the understanding of uptake of microparticulates across the gastrointestinal lymphatics. Advanced Drug Delivery Reviews 2001;50(1-2) 107-142.

[65] Des Rieux A, Fievez V, Theate I, Mast J, Preat V, Schneider Y-J. An improved in vitro model of human intestinal follicle-associated epithelium to study nanoparticle transport by M cells. European Journal of Pharmaceutical Sciences 2007;30(5) 380-391.

[66] Aprahamian M, Michel C, Humbert W, Devissaguet J, Damge C: Transmucosal passage of polyalkylcyanoacrylate nanocapsules as a new drug carrier in the small intestine. Biology of the Cell 1987;61(1-2) 69-76. 
[67] Kroll A, Pillukat M, Hahn D, Schnekenburger J. Current in vitro methods in nanoparticle risk assessment: limitations and challenges. European Journal of Pharmaceutics and Biopharmaceutics 2009;72(2) 370-377.

[68] Lilienblum W, Dekant W, Foth H, Gebel T, Hengstler J, Kahl R, Kramer P, Schweinfurth $\mathrm{H}$, Wollin K. Alternative methods to safety studies in experimental animals: role in the risk assessment of chemicals under the new European Chemicals Legislation (REACH). Archives of Toxicology 2008;82(4) 211-236.

[69] Artursson P, Karlson J. Correlation between oral drug absorption in humans and apparent drug permeability coefficients in human intestinal epithelial (Caco-2) cells. Biochemical and Biophysical Research Communications 1991;175(3) 880-885.

[70] Artursson P, Borchardt R. Intestinal drug absorption and metabolism in cell cultures: Caco-2 and beyond. Pharmaceutical Research 1997;14(12) 1655-1658.

[71] Chantret I, Barbat A, Dussaulx E, Brattain MG, Zweibaum A. Epithelial polarity, villin expression, and enterocytic differentiation of cultured human colon carcinoma cells: a survey of 20 cell lines. Cancer Res 1988;48(7) 1936-1942.

[72] Pinto M, Robin-Leon S, Appay M, Kedinger M, Triadou N, Dussaulx E, Lacroix B, Simon-Assmann P, Haffen K, Fogh J, Zweibaum A. Enterocyte-like differentiation and polarization of the human colon carcinoma cell line Caco-2 in culture. Biology of the Cell 1983;47 323-330.

[73] Kraehenbuhl J, Neutra M. Epithelial M cells: differentiation and function. Annual Review of Cell and Developmental Biology 2000;16 301-332.

[74] Sansonetti P, Phalipon A. M cells as ports of entry for enteroinvasive pathogens: mechanisms of interaction, consequences for the disease process. Seminars in Immunology 1999;11(3) 193-203.

[75] Neutra M, Pringault E, Kraehenbuhl J. Antigen sampling across epithelial barriers and induction of mucosal immune responses. Annual Review of Immunology 1996;14 275-300.

[76] Kernéis S, Bogdonona A, Kraehenbuhl JP, Pringault E. Conversion by Peyer's patches lymphocytes of human enterocytes into $\mathrm{M}$ cells that transport bacteria. Science 1997;277(5328) 949-952.

[77] Gullberg E, Leonard M, Karlsson J, Hopkins A, Brayden D, Baird A, Artursson P. Expression of specific markers and particle transport in a new human intestinal M-cell model. Biochemical and Biophysical Research Communications 2000;279(3) 808-813.

[78] Lo D, Tynan W, Dickerson J, Scharf M, Cooper J, Byrne D, Brayden D, Higgins L, Evans C, O'Mahony DJ. Cell culture modeling of specialized tissue: identification of genes expressed specifically by follicle-associated epithelium of Peyer's patch by expression profiling of Caco-2/Raji co-cultures. International Immunology 2004;16(1) 91-99. 
[79] Schulte R, Kerneis S, Klinke S, Bartels H, Preger S, Kraehenbuhl JP, Pringault E, Autenrieth IB. Translocation of Yersinia enterocoltica across reconstituted intestinal epithelial monolayers is triggered by Yersinia invasin binding to beta1 integrins apically expressed on M-like cells. Cell Microbiology 2000;2(2) 173-185.

[80] Owen R, Ermak T. Structural specializations for antigen uptake and processing in the digestive tract. Semininars in Immunopathology 1990;12(2-3) 139-152.

[81] Denker B, Nigam S. Molecular structure and assembly of the tight junctions. American Journal of Physiology 1998;274 (1 Pt2) F1-9.

[82] Turner J. Intestinal mucosal barrier function in health and disease. Nature Reviews Immunology 2009;9(11) 799-809.

[83] Clayburgh D, Shen L, Turner J. A porous defense: the leaky epithelial barrier in intestinal disease. Laboratory Investigation 2004;84(3) 282-291.

[84] Farhadi A, Banan A, Fields J, Keshavarzian A. Intestinal barrier: an interface between health and disease. Journal of Gastroenterology and Hepatology 2003;18(5) 479-497.

[85] Nusrat A, Turner J, Madara J. Molecular physiology and pathophysiology of tight junctions. IV. Regulation of tight junctions by extracellular stimuli: nutrients, cytokines, and immune cells. American Journal of Physiology, Gastrointestinal and Liver Physiology 2000;279(5) G851-857.

[86] Capaldo C, Nusrat A. Cytokine regulation of tight junctions. Biochimica et Biophysica Acta 2009;1788(4) 864-871.

[87] Bailey, C.. A., Bryla, P., Malick, A.W., The use of intestinal epithelial cell culture model, Caco-2, in pharmaceutical development. Advanced Drug Delivery Reviews 1996. 22(1-2) 85-103.

[88] Sonaje K, Lin K, Tseng M, Wey S, Su F, Chuang EY Hsu C, Chen C, Sung H. Effects of chitosan-nanoparticle-mediated tight junction opening on the oral absorption of endotoxins. Biomaterials 2011;32(33) 8712-8721.

[89] Lockman PR, Koziara JM, Mumper RJ, Allen DD. Nanoparticle surface charges alter blood-brain barrier integrity and permeability. J Drug Target. 2004;12(9-10) 635-41.

[90] He C, Hu Y, Yin L, Tang C, Yin C. Effects of particle size and surface charge on cellular uptake and biodistribution of polymeric nanoparticles. Biomaterials 2010;31(13) 3657-3666.

[91] Xiao K, Li Y, Luo J, Lee JS, Xiao W, Gonik AM, Agarwal RG, Lam KS. The effect of surface charge on in vivo biodistribution of PEG-oligocholic acid based micellar nanoparticles. Biomaterials 2011;32(13) 3435-3446.

[92] Yue Z, Wei W, Lv P, Yue H, Wang L, Su Z, Ma G. Surface charge affects cellular uptake and intracellular trafficking of chitosan-based nanoparticles. Biomacromolecules 2011;12(7) 2440-2446. 
[93] Kelf T, Sreenivasan V, Sun J, Kim E, Goldys E, Zvyagin A. Non-specific cellular uptake of surface-functionalized quantum dots. Nanotechnology 2010;21(28) 285105.

[94] Chen L, McCrate J, Lee J, Li H. The role of surface charge on the uptake and biocompatibility of hydroxyapatite nanoparticles with osteoblast cells. Nanotechnology 2011;22(10) 105708.

[95] Lundqvist M, Stigler J, Elia G, Lynch I, Cedervall T, Dawson K. Nanoparticle size and surface properties determine the protein corona with possible implications for biological impact. Proceedings of the National Academy of Sciences of the USA 2008;105(38) 14265-14270.

[96] Schreibelt G, Kooij G, Reijerkerk A, van Doorn R, Gringhuis S, van der Pol S, Weksler B, Romero I, Couraud P, Piontek J, Blasig I, Dijkstra C, Ronken E, de Vries H. Reactive oxygen species alter brain endothelial tight junction dynamics via RhoA, PI3 kinase, and PKB signaling. FASEB Journal 2007;21(13) 3666-3676.

[97] Sheth P, Basuroy S, Li C, Naren A, Rao R. Role of phosphaditylinositol 3-kinase in oxidative stress-induced disruption of tight junctions. Journal of Biological Chemistry 2003, 278(49) 49239-49245.

[98] Ballestri M, Baraldi A, Gatti A M, Furci L, Bagni A, Loria P, Rapaa M, Carulli N, Albertazzi A. Liver and kidney foreign bodies granulomatosis in a patient with malocclusion, bruxism, and worn dental prostheses. Gastroenterology 2001;121(5) 1234-1238.

[99] Sheth P, Delos Santos N, Seth A, LaRusso N, Rao R. Lipopolysaccharide disrupts tight junctions in cholangiocyte monolayers by c-Scc-, TLR4-, and LPB-dependent mechanism. American Journal of Physiology, Gastrointestinal and Liver Physiology 2007;293(1) G308-318.

[100] Loftus EV Jr. Clinical epidemiology of inflammatory bowel disease: incidence, prevalence, and environmental influences. Gastroenterology 2004;126(6) 1504-1517.

[101] Laukoetter M, Nava P, Nusrat A. Role of intestinal barrier in inflammatory bowel disease. World Journal of Gastroenterology 2008;14(3) 401-407.

[102] Teahon K, Smethurst P, Levi A, Menzies I, Bjarnason I. Intestinal permeability in patients with Crohn's disease and their first degree relatives. Gut 1992;33(3) 320-323.

[103] Peeters M, Geypens B, Claus D, Nevens H, Ghoos Y, Verbeke G, Baert F, Vermeire S, Vlietinck R, Rutgeerts P. Clustering of increased small intestinal permeability in families with Crohn's disease. Gastroenterology 1997;113(3) 802-807.

[104] Piche T, Barabara G, Aubert P, Bruley dês Varannes S, Dainese R, Nano J, Cremon C, Strangellini V, de Giorgio R, Galmiche J, Neunlist M. Impaired intestinal barrier integrity in the colon of patients with irritable bowel syndrome: involvement of soluble mediators. Gut 2009;58(2) 196-201.

[105] Eutamene H, Bueno L. Role of probiotics in correction abnormalities of colonic flora induced by stress. Gut 2007;56(11) 1495-1497. 
[106] Schmitz H, Fromm M, Bentzel C, Scholz P, Detjen K, Mankertz J, Bode H, Epple H, Riecken E, Schulzke J. Tumor necrosis factor- $\alpha$ (TNF-alpha) regulates the epithelial barrier in the human intestinal cell line HT-29/B6. Journal of Cell Science 1999;112(Pt 1) $137-146$.

[107] Schulzke J, Ploeger S, Amasheh M, Fromm A, Zeissig S, Troeger H, Richter J, Bojarski C, Shumann M. Fromm M. Epithelial tight junctions in intestinal inflammation. Annals of the New York Academy of Sciences 2009;1165 294-300.

[108] Powell J, Ainley C, Harvey R, Manson I, Kendall M, Sankey E, Dhillon A, Thompson R. Characterization of inorganic microparticles in pigment cells of human gut associated lymphoid tissue Gut 1996;38(3) 390-395

[109] Powell J, Harvey R, Ashwood P, Wolstencroft R, Gershwin M, Thompson R. Immune potentiation of ultrafine dietary particles in normal subjects and patients with inflammatory bowel diseaseJournal of Autoimmunity 2000;14(1) 99-105.

[110] Lomer M, Grainger S, Ede R, Catterall A, Greenfield S, Cowan R, Vicary F, Jenkins A, Fidler H, Harvey R, Ellis R, McNair A, Ainley C, Thompson R, Powell J. Lack of efficacy of a reduced microparticle diet in a multi-centred trial of patients with active Crohn's disease. European Journal of Gastroenterology \& Hepatology 2005;17(3) 377-384.

[111] Gatti A. Biocompatibility of micro- and nano-particles in the colon. Part II. Biomateials 2004;25(3) 385-392.

[112] Kucharzik T, Lugering A, Lugering N, Rautenberg K, Linnepe M, Cichon C, Reichelt R, Stoll R, Schmidt M, Domschke W. Characterization of M cell development during indomethacin-induced ileitis in rats. Alimentary Pharmacology and Therapeutics 2000;14(2) 247-256.

[113] Stone V, Nowack B, Baun A, van den Brink N, Kammer F, Dusinska M, Handy R, Hankin S, Hassellöv M, Joner E, Fernandes T. Nanomaterials for environmental studies: classification, reference material issues, and strategies for physico-chemical characterization. Science of the Total Environment 2010;408(7) 1745-1754.

[114] Bar-Ilan O, Albrecht R, Fako V, Furgeson D. Toxicity assessments of multisized gold and silver nanoparticles in zebrafish embryos. Small 2009;5(16) 1897-1910.

[115] Sayes C, Warheit D. Characterization of nanomaterials for toxicity assessment. Wiley interdisciplinary reviews. Nanomedicine and nanobiotechnology 2009;1(6) 660-670,

[116] Auffan M, Rose J, Wiesner M, Bottero J. Chemical stability of metallic nanoparticles: A parameter controlling their potential cellular toxicity in vitro. Environmental Pollution 2009;157(4) 1127-1133.

[117] Handy R, Henry T, Scown T, Johnston B, Tyler C. Manufactured nanoparticles: their uptake and effects on fish - a mechanistic analysis. Ecotoxicology 2008;17(5) 396-409.

[118] Lynch I, Cedervall T, Lundqvist M, Cabaleiro-Lago C, Linse S, Dawson K. The nanoparticle-protein complex as a biological entity; a complex fluids and surface science 
challenge for the 21st Century. Journal of Colloid and Interface Science 2007;134-135 167-174.

[119] Li N, Lewis P, Samuelson D, Liboni K, Neu J. Glutamine regulates Caco-2 cell tight junction proteins. American Journal of Physiology, Gastrointestinal and Liver Physiology 2004;287(3) G726-733.

[120] Seth A, Basuroy S, Sheth P, Rao R. L-Glutamine ameliorates acetaldehyde-induced increase in paracellular permeability in Caco-2 cell monolayer. American Journal of Physiology, Gastrointestinal and Liver Physiology 2004;287(3) G510-517.

[121] Lindmark T, Nikkila T, Artursson P. Mechanisms of absorption enhancement by medium chain fatty acids in intestinal epithelial Caco-2 cell monolayers. Journal of Pharmacology and Experimental Therapeutics 1995;275(2) 958-964.

[122] Usami M, Muraki K, Iwamoto M, Ohata A, Matsushita E, Miki A. Effect of eicosapentaenoic acid (EPA) on tight junction permeability in intestinal monolayer cells. Clinical Nutrition 2001;20(4) 351-359.

[123] Usami M, Komurasaki T, Hanada A, Kinoshita K, Ohata A. Effect of gamma-linolenic acid or docosahexaenoic acid on tight junction permeability in intestinal monolayer cells and their mechanism by protein kinase $\mathrm{C}$ activation and/or eicosanoid formation. Nutrition 2003;19(2) 150-156.

[124] Suzuki T, Hara H. Role of flavonoids in intestinal tight junction regulation. Journal of Nutritional Biochemistry 2011;22(5) 401-408.

[125] Sergent T, Piront N, Meurice J, Toussaint O, Schneider Y-J. Anti-inflammatory effects of dietary phenolic compounds in an in vitro model of inflamed human intestinal epithelium. Chemico-Biological Interactions 2010;188(3) 659-667.

[126] Labbé D, Provençal M, Lamy S, Boivin D, Gingras D, Béliveau R. The flavonols quercetin, kaempferol, and myricetin inhibit hepatocyte growth factor-Induced medulloblastoma cell migration. Journal of Nutrition 2009;139(4) 646-652.

[127] Guo D, Wu C, Li J, Guo A, Li Q, Jiang H, Chen B, Wang X. Synergistic effect of functionalized nickel nanoparticles and quercetin on inhibition of the SMMC-7721 cells proliferation. Nanoscale Research Letters 2009;4(12) 1395-1402.

[128] Bosi S, da Ros T, Spalluto G, Prato M. Fullerene derivatives: an attractive tool for biological applications. European Journal of Medicinal Chemistry 2003;38(11-12) 913-923.

[129] Schubert D, Dargusch R, Raitano J, Chan S. Cerium and yttrium oxide nanoparticles are neuroprotective. Biochemical and Biophysical Research Communications 2006;342(1) 86-91.

[130] Romieu I. Nutrition and lung health. International Journal of Tuberculosis and Lung Disease 2005;9(4) 362-374 
[131] Vermylen J, Nemmar A, Nemery B, Hoylaerts F. Ambient air pollution and acute myocardial infarction. Journal of Thrombosis and Haemostasis 2005;3(9) 1955-1961.

[132] Amasheh M, Fromm A, Krug SM, Amasheh S, Andres S, Zeitz M, Fromm M, Schulzke JD. TNFalpha-induced and berberine-antagonized tight junction barrier impairment via tyrosine kinase, Akt and NFkappaB signaling. Journal of Cell Science 2010;123(Pt 23) 4145-4155.

[133] Shankar S, Ahmad A, Sastry M. Geranium leaf assisted biosynthesis of silver nanoparticles. Biotechnology Progress 2003;19(6) 1627-1631.

[134] Tripathy A, Raichur M, Chandrasekaran N, Prathna T, Mukherjee A. Process variables in biomimetic synthesis of silver nanoparticles by aqueous extract of Azadirachta indica (Neem) leaves. Journal of nano research 2010;12(1) 237-246.

[135] Raut R, Jaya S, Niranjan D, Vijay B, Kashid S. Photosynthesis of silver nanoparticle using Gliricidia sepium (Jacq.). Current Nanoscience 2009;5(1) 117-122.

[136] Rao R, Basuroy S, Rao V, Karnaky Jr K, Gupta A. Tyrosine phosphorylation and dissociation of occluding-ZO-1 and E-caderin-beta-catenin coplexes from the cytoskeleton by oxidative stress. Biochemical Journal 2002;368(Pt 2) 471-481.

[137] Aggarwal B, Bhardwaj A, Aggarwal R, Seeram N, Shishodia S, Takada Y. Role of resveratrol in prevention and therapy of cancer: preclinical and clinical studies. Anticancer Research 2004;24(5A) 2783-2840.

[138] Jang M, Cai L, Udeani G, Slowing K, Thomas C, Beecher C, Fong H, Farnsworth N, Kinghorn A, Mehta R, Moon R, Pezzuto J. Cancer chemopreventive activity of resveratrol, a natural product derived from grapes. Science 1997;275(5297) 218-220.

[139] Fulda S, Debatin K. Resveratrol modulation of signal transduction in apoptosis and cell survival: a mini-review. Cancer Detection and Prevention 2006;30(3) 217-223.

[140] Donnelly L, Newton R, Kennedy G, Fenwick P, Leung R, Ito K, Russell R, Barnes P. Anti-inflammatory effects of resveratrol in lung epithelial cells: molecular mechanisms. American Journal of Physiology, Lung Cellular and Molecular Physiology 2004;287(4) L774-783.

[141] Martin K, Appel C. Polyphenols as dietary supplements: a double-edged sword. Nutrition and Dietary Supplements 2010;2 1-12.

[142] European Food Safety Authority (EFSA) Scientific Committee; Scientific Opinion on Guidance on the risk assessment of the application of nanoscience and nanotechnologies in the food and feed chain. EFSA Journal 2011;9(5) 2140-2176. 